\title{
Evaluation of Ergonomics and Efficacy of Instruments in Dentistry
}

\author{
Nina Nevala ${ }^{*}, 1,2$, Erja Sormunen ${ }^{1,2}$, Jouko Remes ${ }^{1}$ and Kimmo Suomalainen ${ }^{3}$ \\ ${ }^{1}$ Finnish Institute of Occupational Health, Topeliuksenkatu 41 a A, FI-00250 Helsinki, Finland \\ ${ }^{2}$ University of Jyväskylä, Gerontology Research Centre and Department of Health Sciences, Box 35, FI-40014 \\ University of Jyväskylä, Finland \\ ${ }^{3}$ Institute of Dentistry, P.O. Box 41, FI-00014 University of Helsinki, Helsinki, Finland
}

\begin{abstract}
Purpose: To evaluate the ergonomics and efficacy of five instruments used in dentistry for scaling and root planing.

Methods: This experimental study with a comparative cross-sectional design was carried out during a simulated scaling and root planing task. Seven female dentists and one dental hygienist aged 26-58 years participated. Five instruments were evaluated in a subjective analysis of usability and musculoskeletal strain and with measurements of muscular activity, postures of the upper limbs, and work productivity.

Results: The instruments with the thickest (diameter of $12-14 \mathrm{~mm}$ ) silicon handles caused the lowest perceived strain in both the fingers/palm and the thumb. Work productivity was also the best with the thickest silicon handles. Between the instruments, no statistically significant differences were found for the muscular activity of the four muscle groups studied or for the postures of the wrist and upper arm.

Conclusions: The design and material of dental instruments can affect perceived comfort and work productivity. In scaling and root planing tasks, instruments with thick silicon handles are more usable, cause lower perceived strain, and are more productive than those with thinner handles. The results of this study can be used to aid dental instruments development and selection.
\end{abstract}

Keywords: Dentistry, efficacy, ergonomics, hand instrument, hand tool, productivity, usability.

\section{INTRODUCTION}

Dentists and dental hygienists frequently have musculoskeletal disorders involving the upper limbs [1,2]. Studies show that dentists have a high frequency of fingerrelated and other upper-limb symptoms [1] and a high prevalence of osteoarthrosis involving the distal interphalangeal joints [3]. According to Ding et al. [4], an association exists between the severity of finger joint osteoarthritis and finger joint pain among female dentists and teachers. Furthermore, finger joint osteoarthritis and pain increased the risk of low pinch-grip strength [5]. It is also known that carpal tunnel syndrome is common among dental hygienists [2]. According to Rice et al. [6], there may be a greater risk of developing upper extremity disorders among dental hygienists than among dentists due to the long hours of dental scaling and root planing.

Dentistry demands continuous use of the hands and includes several risk factors involving the upper limbs $[4,7]$. Work-related risk factors for carpal tunnel syndrome include repetitive forceful pinching and non-neutral wrist positions $[8,9]$. Especially dentists use their thumb and their index

Address correspondence to this author at the Finnish Institute of Occupational Health, Ergonomics and Usability, Topeliuksenkatu 41 a A, FI-00250 Helsinki, Finland; Tel: +358 40 7344166, +358 40 7344166;

E-mail: nina.nevala@ttl.fi and middle fingers in precision gripping [10]. In addition, a long work history of dental filling and root canal treatment, as well as a high body mass index (BMI), seems to be associated with frequent finger symptoms that are perceived as being vibration-related by dentists [11].

Ergonomic studies show alternative means of reducing risk exposure [12]. Smith et al. [13] showed that alternative methods for viewing patients' teeth (e.g. use of video camera and monitor to view the mouth) significantly reduce the muscle activity, neck flexion, and discomfort of workers when compared with the use of a direct view. According to Dong et al. [7], ergonomically designed dental instruments for scaling and root planing may help reduce the prevalence of carpal tunnel syndrome among dental practitioners. They also showed that an instrument handle with a tapered, round shape and a 10-mm diameter required the least muscle load and pinch force during simulated periodontal work.

Only a few studies have addressed the ergonomics of dental instruments. The aim of our study was to evaluate in a simulated setting the ergonomics and efficacy of five differently designed handles of instruments for dental scaling and root planing. 


\section{MATERIAL AND METHODOLOGY}

\section{Participants}

Seven female dentists and one female dental hygienist, aged 26-58 years, from workplaces in the public or private sector of the health care system participated in the study (Table 1). All of the women were right handed, healthy, and in the normal weight range.

All of the participants were informed of the details of the experimental procedures and the possible discomfort associated with the physical experiments. They all gave their written informed consent. Permission for video-recordings of the experimental settings was also obtained from each participant.

Table 1. Basic Background Information on the Participants. (n=8) (Standard Deviation, SD)

\begin{tabular}{|c|c|c|c|}
\hline Variable & Mean & SD & Range \\
\hline \hline Age (years) & 40 & 10 & $26-58$ \\
\hline Height $(\mathrm{cm})$ & 169 & 8 & $156-183$ \\
\hline Weight $(\mathrm{kg})$ & 60 & 7 & $53-75$ \\
\hline Body mass index $\left(\mathrm{kg} / \mathrm{m}^{2}\right)$ & 22 & 2 & $19-23$ \\
\hline Work experience (years) & 12 & 9 & $3-30$ \\
\hline
\end{tabular}

\section{Tested Instruments}

This study evaluated five different models of Gracey finishing curettes, typical instruments used for periodontal treatment (Fig. 1). The models and characteristics of the instruments (A-E) are shown in Table 2.

\section{Study Design}

This was an experimental study with a comparative cross-sectional design carried out using a simulated task of scaling and root planing. The 2-hour test simulation was planned in a participative way together with dentists and researchers. The measurements of each participant were carried out with all five scaling instruments in random order during the same day in a simulated setting in a dental unit at the Institute of Dentistry, University of Helsinki (Fig. 2). All of the participants were experienced professionals who were familiar with the procedures required for their job. During the study, the women worked with each instrument (A-E) for 2 minutes.

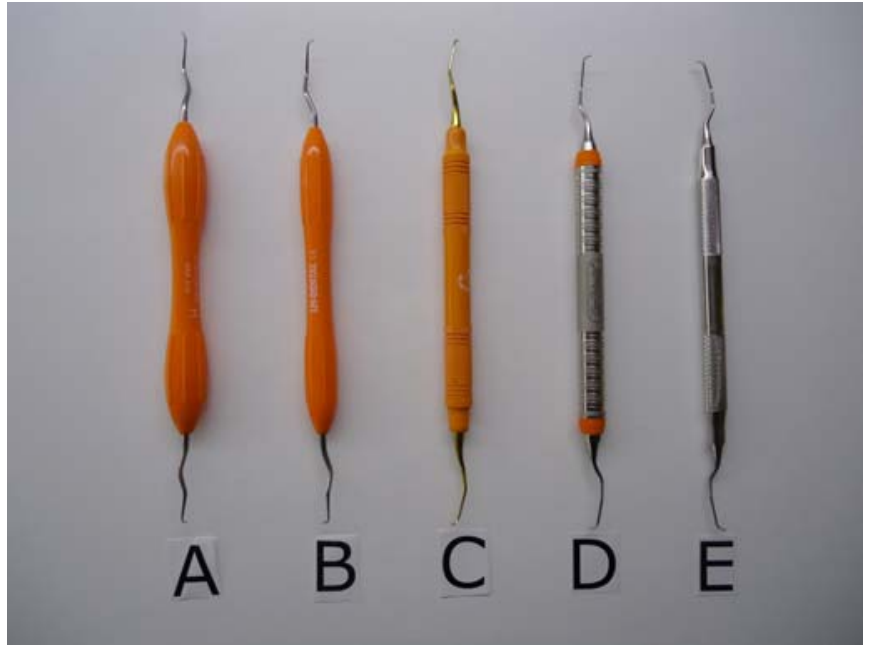

Fig. (1). The tested five instruments (A-E).

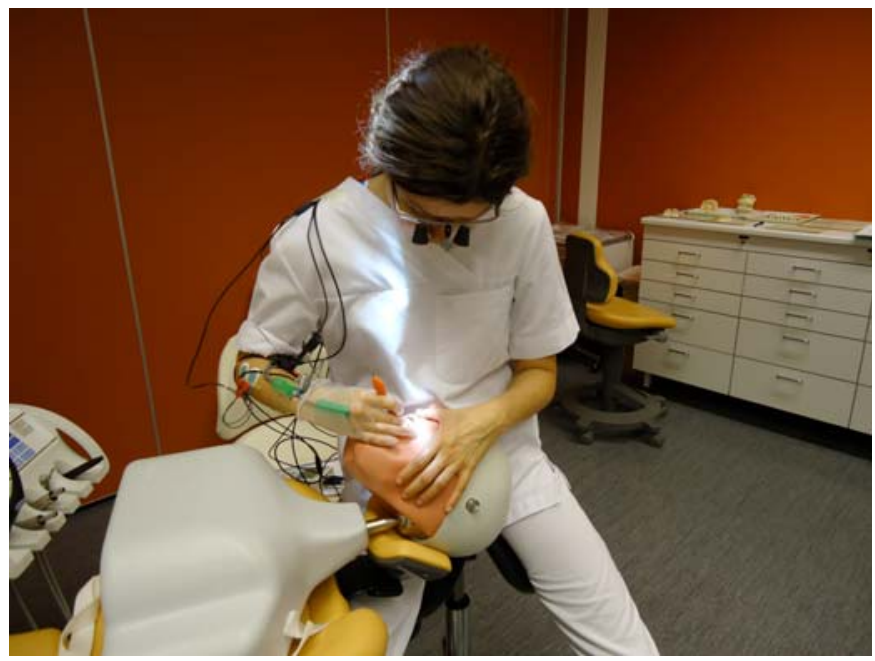

Fig. (2). The simulated work situation using plastic model teeth attached to a phantom head fixed to a dental chair.

The participants were given the freedom to choose the method with which they would complete their tasks. In the beginning of the measurements, they were allowed to adjust the chair and the dental unit according to their preferences. The adjustments were kept constant throughout the study setting.

Periodontal instruments were used on plastic model teeth attached to a phantom head (Frasaco, Germany) fixed to a Sirona model D3390 dental unit (Sirona, Austria). The

Table 2. Tested Instruments (Gracey 11/12 Finishing Curettes) with Five Different Types of Handles (A-E)

\begin{tabular}{|c|c|c|c|c|c|}
\hline & $\begin{array}{c}\text { A } \\
\text { (LM 211-212 } \\
\text { Prototype) }\end{array}$ & $\begin{array}{c}\text { B } \\
\text { (LM 211-212 } \\
\text { XSi) }\end{array}$ & $\begin{array}{c}\text { C } \\
\text { (American Eagle Gracey } \\
\text { Access 11-12 XP, AE GA 11-12 XPX) }\end{array}$ & $\begin{array}{c}\text { E } \\
\text { (Hu-Friedy SAS 11/ } \\
\text { 1273 \#7 HDL) }\end{array}$ & $\begin{array}{c}\text { DHu-Friedy SAS11- } \\
\text { 124 4 HDL) }\end{array}$ \\
\hline \hline Weight $(\gamma)$ & 19 & 16 & 13 & 21 & 171 \\
\hline Length $(\mathrm{mm})$ & 173 & 173 & 175 & 9.5 & 171 \\
\hline Diameter of the handle $(\mathrm{mm})$ & $14.2^{1}$ & $11.7^{1}$ & 10.8 & 108 \\
\hline Length of the handle $(\mathrm{mm})$ & 110 & 110 & plastic & metal & 108 \\
\hline Material of the handle & silicon & silicon & metal \\
\hline
\end{tabular}


surfaces apical to the cemento-enamel junction of the model teeth were painted with black nail polish to imitate calcified deposits on tooth surfaces. The mesial surface of the first upper molar on the right-hand side (tooth 16) was chosen as the target of the instrumentation process.

\section{Measurements}

The instruments were evaluated with the use of a subjective analysis of usability and musculoskeletal strain and objective measurements of muscular activity, postures of the upper limbs, and work productivity. In the subjective evaluation, the participants responded to a query immediately after the completion of the task with each scaling instrument. The query included visual analogue scales (VASs) to evaluate the usability (6 usability features, 18 usability components) of the product [14-16]. The VAS is a $100-\mathrm{mm}$ long continuous line with end points anchored by 0 (very poor) and 100 (very good). The VAS score is the measured distance (expressed in millimeters) from the lefthand end of the scale. The participants were asked to mark the point on the line that indicated their evaluation of the strain or usability component in question. They were allowed to offer written comments on the questionnaire about the usability features of the instruments.

VASs were also used to evaluate the perceived musculoskeletal strain in six body parts (neck, shoulder, upper arm, lower arm, fingers/palm, thumb) [14-17].

Muscular activity was measured with surface electromyography (EMG) (ME6000, Mega Electronics, Kuopio, Finland) during the scaling process [18]. It was measured on the right side of the body ( $m$. flexor pollicis brevis, $m$. extensor digitorum, $m$. flexor carpi radialis, and $m$. trapezius pars descendens). The positions of the electrodes were defined according to the recommendations of Delagi and Perotto [19] and Zipp [20]. The EMG signals from the skin above the working muscles were acquired with a sample rate of $1000 \mathrm{~Hz}$. The measured signal was amplified 2000 times (preamplifier situated $10 \mathrm{~cm}$ from the measuring electrodes), and the signal band, 20-500 Hz, was full wave-rectified and averaged with a 0.1 -second time constant.

From the EMG data, the mean amplitude values $(\mu \mathrm{V})$ were analyzed. Muscular activity during the work was defined as the percentage of maximal EMG activity (\%EMG) by calculating the EMG activity during work in relation to the activity measured during a maximal voluntary isometric contraction (MVC). Prior to the performance of the scaling task, MVCs were recorded from the four aforementioned muscles. The tests were carried out with the participant in a sitting position. During the MVC of the $m$. flexor pollicis brevis, the participant placed her elbow on the table at a flexion of $100-110^{\circ}$ while holding a scaling instrument in her hand. She then maximally pressed the handle of the instrument [17]. During the MVC of the $m$. extensor digitorum and $m$. flexor carpi radialis, the participant's forearm was in pronation and supination, respectively, on the table, and she raised her hand (in the direction of wrist extension and flexion, respectively) against the researcher's resistance on the dorsal side and volar side of her hand. During the MVC of the $m$. trapezius pars descendens, the participant held her upper extremities straight at the side of her body and elevated her shoulders against the researcher's resistance. Each participant was allowed one practice trial; thereafter two trials were performed. The amplitude of the MVC $(\mu \mathrm{V})$ was calculated after the participant had reached the peak level of contraction and held it for 3-4 seconds. The muscle contraction and EMG amplitude level remained stable during the test for maximal isometric contractions, which was one criterion for choosing the maximal EMG activity as a reference [17].

The upper-extremity ranges of motion were measured on the dominant side for wrist extension-flexion, ulnar-radial deviations, lower-arm and supination-pronation, as well as for abduction and flexion of the upper arm. The wrist and lower-arm movements were measured using a twin-axis electrogoniometer and a single-axis torsiometer, respectively. The upper-arm ranges of motion were registered using an inclinometer (Biometrics Ltd, Cwmfelinfach, UK) $[17,21]$. The sensors were attached to the back of the wrist with skin adhesive tape. One end block of the twin-axis goniometer was attached in line with the third metacarpal bone, and the other was attached on the midline dorsal side of the distal lower arm. The reference position ( 0 degrees of flexion and deviation) was recorded with the participant in a standing position with her hands and upper extremities relaxed at the side of her body. The distal end block of the single-axis torsiometer was attached on the palmar surface of the forearm in line with the third metacarpal bone, and the other end was attached below the medial epicondylitis at the proximal part of forearm. The inclinometer was attached above the insertion of the shoulder muscle. The output from the goniometer was sampled with a data logger (ME6000, Mega Electronics, Kuopio, Finland) at a frequency of $1000 \mathrm{~Hz}$, using the averaged mode and a time constant of 0.1 second. From the electrogoniometer data, the mean values of degree $\left(^{\circ}\right)$ were analyzed $[17,21]$.

Work productivity was evaluated with an objective method. The outcome of the scaling and root planing process was analyzed by photographing the mesial surfaces of the model teeth after the instrumentation [7]. The teeth were removed from the models and placed one by one in a mold produced from dental impression material to ensure standard positioning of the teeth while being photographed. With the aid of a millimeter grid, the percentage of the paint that was removed during the test period was determined and used as the measure of the outcome of the procedure [7].

The results were analyzed using the SPSS software for Windows (version 18.0 SPSS Inc., Chicago, IL, USA). The data are presented as means and standard deviations (SD) for the background information or as means with $95 \%$ confidence intervals (CIs) for the data on perceived usability and musculoskeletal strain. The Shapiro-Wilk test was used to test the normally distributed variables the one-way analysis of variance (ANOVA), followed by the Bonferroni post-hoc test, was performed. For the non-normally distributed variables, the non-parametric Kruskall-Wallis, one-way ANOVA was performed. Thereafter, the significance between the groups was determined with the use of the Mann-Whitney U-test. If the mean value of the specific variable differed from the confidence intervals $(95 \%$ CIs) of the variables in interest, the means differ statistically significantly $(\mathrm{p}<.05)$. 


\section{RESULTS}

The two most usable instruments according to the participants' perceived assessments were those with the thickest silicon handles (A, B) (Table 3). The usability of these two scaling instruments was statistically better with respect to most features than the usability of the worst instrument (E) with the thin metallic handle. The instrument with the thickest handle (A) was the best with regard to eight usability components, and the instrument with second thickest handle (B) was best for nine usability components. Respectively, the participants considered one feature, the grasp, to be equal for these two instruments (A, B).

The participants reported that the instruments with the thickest and second thickest silicon handles (A, B) caused the lowest strain, both for the fingers/palm and for the thumb. Perceived strain in these body parts was statistically significantly different between the instruments with the thickest handles (A, B) when they were compared with the instrument with the thickest metallic handle (E) (Table 4). Otherwise, no significant differences in the perceived musculoskeletal strain of body parts were observed between the instruments.

There were no statistically significant differences in the muscular activity of the four muscle groups between the tested instruments (A-E) (Table 5). In addition, no significant differences were found for the postures of the wrist and upper arm between the tested instruments (A-E) (Table 6).

The measured work productivity was best when the instrument (B) with the second thickest silicon handle was used (Table 7). In addition, there was a statistically significant difference in work productivity between the instrument with the second thickest silicon handle (B) and the heaviest instrument with the thick metallic handle (D). Work productivity was the worst when the heaviest metallic instrument (D) was used.

\section{DISCUSSION}

The two scaling instruments with the thickest silicon handles (A, B) were the most usable instruments according to the 18 components of the usability features analyzed in this study. The usability results of these two instruments (A, B) were statistically significantly better than the usability results of the instrument with a thinnest metallic handle (E). The VAS proved to be a suitable and easy-to-understand method for use in this type of study, and it has been used also in other ergonomic studies in health care [15-17].

According to the subjective evaluation, the use of the thinnest metallic instrument (E) caused the most

Table 3. Perceived Usability (VAS, Visual Analogue Scale, $\mathbf{0}=$ Very Poor, $100=$ Very Good) as Rated by the Participants $(\mathrm{n}=\mathbf{8})$ After Using the Five Instruments with Different Types of Handles (A-E). (95\% Confidence Interval, 95\% CI)

\begin{tabular}{|c|c|c|c|c|c|c|}
\hline \multirow{2}{*}{ Usability Feature } & \multicolumn{6}{|c|}{ Instrument } \\
\hline & $\begin{array}{c}\text { Usability } \\
\text { Component }\end{array}$ & $\underset{\text { Mean }(95 \% \text { CI })}{\text { (95 }}$ & $\begin{array}{c}\text { B } \\
\text { Mean }(95 \% \text { CI })\end{array}$ & $\underset{\operatorname{Mean}(\mathbf{9 5 \%} \mathrm{CI})}{\mathrm{C}}$ & $\begin{array}{c}\text { D } \\
\text { Mean }(95 \% \text { CI })\end{array}$ & $\underset{\text { Mean }(95 \% \text { CI })}{\mathbf{E}}$ \\
\hline \multirow{5}{*}{ Design } & Design of handle & $78(62-94)^{1}$ & $81(64-98)^{2}$ & $56(28-83)$ & $65(44-86)$ & $49(22-76)$ \\
\hline & Design of working part & $81(65-97)^{1}$ & $75(50-100)^{2}$ & 75 (50-99) & $77(62-91)$ & $46(20-72)$ \\
\hline & Fit to hand & $70(47-93)^{1}$ & $82(64-99)^{2}$ & $53(24-82)$ & $62(37-88)$ & $42(19-66)$ \\
\hline & Esthetics & $83(69-97)^{1}$ & $77(63-90)$ & $68(52-85)$ & $69(53-86)$ & $61(45-77)$ \\
\hline & Color code & $90(82-97)^{1}$ & $87(73-101)^{2}$ & $86(70-102)$ & $77(63-91)$ & $23(3-42)$ \\
\hline \multirow{3}{*}{ Measurements } & Length of handle & $83(68-98)$ & $82(64-100)$ & $69(49-88)$ & $69(45-94)$ & $66(45-86)$ \\
\hline & Length of working part & $83(72-93)^{1}$ & $78(60-95)^{2}$ & $76(53-99)$ & $79(68-90)$ & $54(37-71)$ \\
\hline & Circumference of handle & $77(60-94)$ & $82(67-98)^{2}$ & $64(39-90)$ & $68(45-91)$ & $43(11-76)$ \\
\hline \multirow{2}{*}{ Material } & Material of handle & $91(85-98)^{1}$ & $92(84-99)^{2,3,4}$ & $58(36-80)$ & $46(25-67)$ & $39(19-58)$ \\
\hline & Surface pattering & $80(67-93)^{1}$ & $89(81-97)^{2,3,4}$ & $60(38-82)$ & $59(38-79)$ & $45(29-61)$ \\
\hline \multirow{4}{*}{ Function } & Balance of instrument & $84(73-95)$ & $82(64-100)$ & $67(47-88)$ & $73(57-88)$ & $64(40-87)$ \\
\hline & Sensibility & $82(69-96)^{1}$ & $80(61-99)^{2}$ & $74(48-100)$ & $82(69-94)$ & $52(32-72)$ \\
\hline & Preciseness & $85(77-94)^{1}$ & $86(73-98)^{2}$ & $75(48-101)$ & $79(69-90)$ & $56(35-77)$ \\
\hline & Turnability & $81(69-93)$ & $82(70-94)$ & $65(38-92)$ & $75(55-95)$ & $60(32-89)$ \\
\hline \multirow{3}{*}{ Strain } & Need for force & $78(62-94)^{1}$ & $69(52-86)^{2}$ & $59(31-87)$ & $56(34-79)$ & $44(21-68)$ \\
\hline & Grasp & $85(75-95)^{1}$ & $85(70-100)^{2,3}$ & $62(34-90)$ & $63(45-80)$ & $45(20-70)$ \\
\hline & Working comfort & $80(69-90)^{1}$ & $82(65-98)^{2}$ & $65(38-92)$ & $70(49-91)$ & $35(15-56)$ \\
\hline General & Overall evaluation & $83(69-96)^{1}$ & $85(72-98)^{2,3}$ & $67(44-90)$ & $69(53-84)$ & $41(17-66)$ \\
\hline
\end{tabular}

${ }^{1}$ Statistically significant difference between scaling instruments $\mathrm{A}$ and $\mathrm{E}$.

${ }^{2}$ Statistically significant difference between scaling instruments B and E.

${ }^{3}$ Statistically significant difference between scaling instruments B and D.

${ }^{4}$ Statistically significant difference between scaling instruments B and C. 
Table 4. Perceived Musculoskeletal Strain (Visual Analogue Scale, VAS, $0=$ No Strain, $100=$ Extreme Strain) in Six Body Parts of the Participants $(n=8)$ After Using the Five Instruments with Different Types of Handles (A-E). (95\% Confidence Interval, $95 \% \mathrm{CI}$ )

\begin{tabular}{|c|c|c|c|c|c|}
\hline \multicolumn{7}{|c|}{ Instrument } \\
\hline Body Part & $\begin{array}{c}\text { A } \\
\text { Mean (95\% CI) }\end{array}$ & $\begin{array}{c}\text { B } \\
\text { Mean (95\% CI) }\end{array}$ & $\begin{array}{c}\text { C } \\
\text { Mean (95\% CI) }\end{array}$ & $\begin{array}{c}\text { D } \\
\text { Mean (95\% CI) }\end{array}$ & Mean (95\% CI) \\
\hline \hline Neck & $27(9-45)$ & $25(7-43)$ & $29(12-45)$ & $26(5-46)$ & $28(14-42)$ \\
\hline Shoulder & $27(10-44)$ & $28(7-49)$ & $31(12-51)$ & $28(9-47)$ & $34(17-50)$ \\
\hline Upper arm & $20(4-37)$ & $26(5-46)$ & $26(4-47)$ & $21(1-42)$ & $27(9-46)$ \\
\hline Lower arm & $27(8-45)$ & $30(9-51)$ & $31(10-52)$ & $26(8-45)$ & $37(17-58)$ \\
\hline Fingers and palm & $29(9-50)^{1}$ & $25(5-46)^{2}$ & $38(13-63)$ & $32(11-54)$ & $33(37-69)$ \\
\hline Thumb & $41(20-63)^{1}$ & $32(11-53)^{2}$ & $42(18-67)$ & $33(13-53)$ & $68(54-81)$ \\
\hline
\end{tabular}

${ }^{1}$ Statistically significant difference between scaling instruments $\mathrm{A}$ and $\mathrm{E}$.

${ }^{2}$ Statistically significant difference between scaling instruments B and E.

Table 5. Muscular Activity (\%EMG) in the Right Upper Limb and the Shoulder Region of the Participants (n=8) During the Use of the Five Instruments with Different Handles (A-E). (Standard Deviation, SD)

\begin{tabular}{|c|c|c|c|c|c|c|}
\hline \multirow{2}{*}{ Body Part (Muscle) } & \multicolumn{5}{|c|}{ Instrument } & \multirow[b]{2}{*}{ p-Value } \\
\hline & $\begin{array}{c}\text { A } \\
\text { Mean (SD) }\end{array}$ & $\begin{array}{c}\text { B } \\
\text { Mean (SD) }\end{array}$ & $\begin{array}{c}\text { C } \\
\text { Mean (SD) }\end{array}$ & $\underset{\text { Mean (SD) }}{\text { D }}$ & $\begin{array}{c}\mathbf{E} \\
\text { Mean (SD) }\end{array}$ & \\
\hline $\begin{array}{c}\text { Thumb } \\
\text { (M. Flexor Pollicis Brevis) }\end{array}$ & $\begin{array}{c}21.9 \\
(11.1)\end{array}$ & $\begin{array}{c}20.3 \\
(11.8)\end{array}$ & $\begin{array}{c}21.0 \\
(14.0)\end{array}$ & $\begin{array}{c}17.8 \\
(13.4)\end{array}$ & $\begin{array}{c}25.0 \\
(12.1)\end{array}$ & 0.121 \\
\hline $\begin{array}{c}\text { Wrist Flexors } \\
\text { (M. Flexor Digitorum Superficialis) }\end{array}$ & $\begin{array}{l}11.9 \\
(3.9)\end{array}$ & $\begin{array}{l}13.0 \\
(5.3)\end{array}$ & $\begin{array}{l}12.6 \\
(4.4)\end{array}$ & $\begin{array}{l}12.5 \\
(5.1)\end{array}$ & $\begin{array}{l}12.4 \\
(4.2)\end{array}$ & 0.998 \\
\hline $\begin{array}{l}\text { Wrist Extensors } \\
\text { (M. Extensor Digitorum) }\end{array}$ & $\begin{array}{l}11.8 \\
(5.6)\end{array}$ & $\begin{array}{l}11.9 \\
(6.1)\end{array}$ & $\begin{array}{l}11.9 \\
(6.5)\end{array}$ & $\begin{array}{l}12.0 \\
(6.6)\end{array}$ & $\begin{array}{l}12.6 \\
(8.0)\end{array}$ & 0.979 \\
\hline $\begin{array}{c}\text { Shoulder } \\
\text { (Trapezius pars Descendens) }\end{array}$ & $\begin{array}{l}6.1 \\
(6.6)\end{array}$ & $\begin{array}{c}4.7 \\
(3.8)\end{array}$ & $\begin{array}{c}5.9 \\
(5.8)\end{array}$ & $\begin{array}{l}5.1 \\
(4.4)\end{array}$ & $\begin{array}{l}6.1 \\
(4.7)\end{array}$ & 0.987 \\
\hline
\end{tabular}

*One-way ANOVA, Kruskall-Wallis.

musculoskeletal strain in the thumb during the use of the instruments. The least perceived strain was reported when the second thickest silicon (B) and the thick metallic (D) instruments were used. This result is in accordance with that of the study carried out by Dong et al. [7]. It is known that the use of a thick instrument decreases the strain of thumb in a pinch grip. This decrease can be due to the more neutral posture of the thumb when a thick instrument is used. Therefore it is important to decrease the muscle activity needed in a pinch grip. This is one way to lower the risk of finger arthrosis, which causes pain and decreases finger force $[5,7]$. It is also important especially for dental hygienists, whose work includes scaling more than dentists' work does $[2,6]$.

No statistically significant differences in the muscle activity of the participants were found for the five instruments. The results are in accordance with the results of Dong et al. [7], who found no statistically significant differences in muscular activity between scaling instruments with thicker (diameter $10 \mathrm{~mm}$ ) and thinner (diameter $7 \mathrm{~mm}$ ) handles [7].

According to the objective measurements, work productivity was best when the instrument (B) with the second thickest silicon handle was used. In earlier ergonomic studies, both the objective photographing method [7] and subjective analyses [17] have been used to analyze work productivity. In objective productivity measurements, the mesial surface of the first upper molar on the right-hand side (tooth 16) was chosen as the target for scaling. Because of the immediate proximity of the duct of the parotid gland, it is a typical site for the accumulation of dental calculus. In addition, the surfaces of this tooth are easily distinguished from each other because of the special morphological character of the mesiopalatal surface.

This study was planned in cooperation with researchers, manufacturers, and experienced dentists. The university dental clinic was an excellent testing environment, because the dental unit, the phantom head, and the plastic model teeth were available. In this study, the sample size was small but quite equal with several other usability studies [16, 17]. The participants were well motivated, and they gave several (confidential) ideas for product development. The test simulation was designed with the cooperation of experienced dentists, and the used research methods have also been employed in other ergonomic studies in health care [15-17]. The usability variables were selected and re-designed together with dentists and researchers while taking into account the results of earlier studies [7, 17]. 
Table 6. Posture (Angle) of the Right Upper Limb of the Participants (n=8) During the Use of the Five Instruments with Different Types of Handles (A-E). (Standard Deviation, SD)

\begin{tabular}{|c|c|c|c|c|c|c|}
\hline \multirow{2}{*}{ Variable } & \multicolumn{6}{|c|}{ Scaling Instrument } \\
\hline & $\begin{array}{c}\text { A } \\
\text { Mean (SD) }\end{array}$ & $\begin{array}{c}\text { B } \\
\text { Mean (SD) }\end{array}$ & $\begin{array}{c}\text { C } \\
\text { Mean (SD) }\end{array}$ & $\begin{array}{c}\text { D } \\
\text { Mean (SD) }\end{array}$ & $\begin{array}{c}\mathbf{E} \\
\text { Mean (SD) }\end{array}$ & p-Value* \\
\hline Wrist extension & $\begin{array}{c}11.8 \\
(11.1)\end{array}$ & $\begin{array}{l}9.8 \\
(8.3)\end{array}$ & $\begin{array}{c}9.1 \\
(7.4)\end{array}$ & $\begin{array}{c}13.4 \\
(10.9)\end{array}$ & $\begin{array}{l}15.1 \\
(9.2)\end{array}$ & 0.698 \\
\hline Ulnar deviation of wrist & $\begin{array}{c}0.9 \\
(5.8)\end{array}$ & $\begin{array}{c}0.4 \\
(8.3)\end{array}$ & $\begin{array}{c}0.8 \\
(5.4)\end{array}$ & $\begin{array}{c}0.1 \\
(6.2)\end{array}$ & $\begin{array}{c}2.3 \\
(8.7)\end{array}$ & 0.971 \\
\hline Pronation of wrist & $\begin{array}{c}19.3 \\
(11.2)\end{array}$ & $\begin{array}{c}19.6 \\
(10.4)\end{array}$ & $\begin{array}{l}21.4 \\
(10)\end{array}$ & $\begin{array}{c}18.6 \\
(10.3)\end{array}$ & $\begin{array}{c}20.3 \\
(10.6)\end{array}$ & 0.982 \\
\hline Abduction of upper arm & $\begin{array}{c}6.4 \\
(16.2)\end{array}$ & $\begin{array}{c}8.6 \\
(18.2)\end{array}$ & $\begin{array}{c}8 \\
(19.5)\end{array}$ & $\begin{array}{c}8.8 \\
(17.5)\end{array}$ & $\begin{array}{c}9.9 \\
(17)\end{array}$ & 0.988 \\
\hline Flexion of upper arm & $\begin{array}{l}3.9 \\
(9)\end{array}$ & $\begin{array}{c}3.3 \\
(10.2)\end{array}$ & $\begin{array}{c}4.5 \\
(11.3)\end{array}$ & $\begin{array}{l}4.1 \\
(8)\end{array}$ & $\begin{array}{c}1.5 \\
(9.6)\end{array}$ & 0.902 \\
\hline
\end{tabular}

*One-way ANOVA, Kruskall-Wallis.

Table 7. Work Productivity of the Participants (n=8), Evaluated as the Percentage of Tooth Surface Cleaned After Scaling with Five Instruments (A-E). (95\% Confidence Interval, 95\% CI)

\begin{tabular}{|c|c|c|c|c|c|}
\hline & \multicolumn{5}{|c|}{ Scaling Instrument } \\
\hline & $\begin{array}{c}\text { A } \\
\text { Mean }(95 \% \text { CI })\end{array}$ & $\begin{array}{c}\text { B } \\
\text { Mean }(95 \% \text { CI })\end{array}$ & $\begin{array}{c}\mathrm{C} \\
\operatorname{Mean}(95 \% \mathrm{CI})\end{array}$ & $\begin{array}{c}\text { D } \\
\text { Mean }(95 \% \text { CI })\end{array}$ & $\begin{array}{c}\mathbf{E} \\
\text { Mean }(95 \% \mathrm{CI})\end{array}$ \\
\hline Cleaned surface of tooth, $(\%)$ & $56(44-68)^{1}$ & $61(53-69)^{2}$ & $53(43-64)$ & $41(30-53)$ & $52(41-64)$ \\
\hline
\end{tabular}

${ }^{1}$ Statistically significant difference between scaling instruments A and D.

${ }^{2}$ Statistically significant difference between scaling instruments B and D.

This paper proposes that scaling instruments with thick silicon handles are the most ergonomic and usable and that work productivity with these instruments is good. However, also other ergonomic improvements in dentistry are needed to decrease musculoskeletal exposure. These improvements should focus on the work organization, work schedules, possibilities to affect one's own work, pauses, work spaces, the dental unit, and work tools. More scientific knowledge is needed about the effectiveness of ergonomic improvements in decreasing musculoskeletal exposure.

\section{CONCLUSIONS}

This study showed that the design and material of handles of dental instruments can affect perceived comfort and work productivity. The use of instruments with thick (diameter 12-14 $\mathrm{mm}$ ) silicon handles were found to be more usable and cause lower perceived musculoskeletal strain. In addition, the use of these instruments was more productive than the use of instruments with thinner handles in a scaling task. The results of this study can be used to aid dental instruments development and selection.

\section{CONFLICT OF INTEREST}

The authors confirm that there is no conflict of interest with the content of this article.

\section{ACKNOWLEDGEMENTS}

The authors wish to thank the Institute of Dentistry, University of Helsinki, for providing the opportunity for this study. The authors would like to thank the volunteer dentists and dental hygienist who made this project possible. Financial support was provided by the Finnish Work Environment Fund.

\section{REFERENCES}

[1] Åkesson I, Schütz A, Horstmann V, Skerfviing S, Moritz U. Musculoskeletal symptoms among dental personnel; lack of association with mercury and selenium status, overweight, and smoking. Swed Dent J 2000; 24: 23-38.

[2] Anton D, Rosecrance J, Merlino L, Cook T. Prevalence of musculoskeletal symptoms and carpal tunnel syndrome among dental hygienists. Am J Ind Med 2002; 42(3): 248-57.

[3] Lehto TU, Rönnemaa TE, Aalto TV, Helenius HY Roentgenological arthrosis of the hand in dentists with reference to manual function. Community Dent Oral Epidemiol 1990; 18: 3741.

[4] Ding H, Solovieva S, Vehmas T, Riihimäki H, Leino-Arjas P. Finger joint pain in relation to radiographic osteoarthritis and joint location - a study of middle-aged female dentists and teachers. Rheumatology 2007; 46: 1502-5.

[5] Ding H, Solovieva S, Vehmas T, Takala E-P, Leino-Arjas P. Hand osteoarthritis and pinch grip strength among middle-aged female dentists and teachers. Scand J Rheumatol 2010; 39(1): 84-7.

[6] Rice VJ, Nindl B, Pentikis JS. Dental workers, musculoskeletal cumulative trauma, and carpal tunnel syndrome, who is at risk? A pilot study. Int J Occup Safety Ergon 1996; 2(3): 218-33.

[7] Dong H, Loomer P, Barr A, LaRoche C, Young E, Rempel D. The effect of tool handle shape on hand muscle load and pinch force in a simulated dental scaling task. Appl Ergon 2007; 38: 525-31.

[8] Kao SY. Carpal tunnel syndrome as an occupational disease. J Am Board Fam Pract 2003; 16(6): 533-42.

[9] Nathan PA, Meadows KD, Istvan JA. Predictors of carpal tunnel syndrome: an 11-year study of industrial workers. J Hand Surg 2002; 27(4): 644-51.

[10] Fish DR, Morris-Allen DM. Musculoskeletal disorders in dentists. N Y State Dent J 1998; 64: 44-8. 
[11] Rytkönen E, Sorainen E, Leino-Arjas P, Solovieva S. Hand-arm vibration exposure of dentists. Int Arch Occup Environ Health 2006; 79: 521-7.

[12] Sanders MA, Turcotte CM. Strategies to reduce work-related musculoskeletal disorders in dental hygienists: two case studies. J Hand Ther 2002; 15(4): 363-74

[13] Smith CA, Sommerich CM, Mirka GA, George MC. An investigation of ergonomic interventions in dental hygiene work. Appl Ergon 2002; 33: 175-84

[14] Price D, McGrath PA, Rafii A, Buckinham B. The validation of visual analogue scale as ratio scale measure for chronic and experimental pain. Pain 1983; 17: 45-56.

[15] Nevala N, Ketola R. Birthing support for midwives and mothers ergonomic testing and product development. Ergon Open J 2012; 5: 28-34
[16] Toivonen R, Choi D-S, Nevala N. Ergonomics product development of a mobile workstation for health care. J Usability Stud 2011; 7: 40-50.

[17] Lintula M, Nevala N. Ergonomics and the usability of mechanical single-channel liquid dosage pipettes. Int J Ind Ergon 2006; 36 : 257-63.

[18] Remes A, Rauhala E, Hänninen O. Fully rectified, integrated, band (Frib-) EMG analysis in quantifying muscle activity. Development of a new field equipment. Acta Physiol Scand 1984; 537: 65-70.

[19] Delagi EF, Perotto A. Anatomic guide for the electromyographer. The limbs. Springfield (IL): Charles C Thomas 1980.

[20] Zipp P. Recommendations for the standardization of lead positions in surface electromyography. Eur J Appl Physiol Occup Physiol 1982; 50: 41-54.

[21] Buchholz B, Wellman H. Practical operation of a biaxial goniometer at the wrist joint. Hum Factors 1997; 39: 119-29.

Received: February 21, 2013

Revised: April 26, 2013

Accepted: April 29, 2013

(C) Nevala et al.; Licensee Bentham Open.

This is an open access article licensed under the terms of the Creative Commons Attribution Non-Commercial License (http://creativecommons.org/licenses/by$\mathrm{nc} / 3.0 /$ ) which permits unrestricted, non-commercial use, distribution and reproduction in any medium, provided the work is properly cited. 